\title{
Inkontinensia Urin pada Anak
}

\author{
Taralan Tambunan
}

Secara umum gangguan berkemih yang disebut mengompol dapat dibagi dalam dua kelompok yaitu enuresis dan inkontinensia urin. Enuresis dianggap sebagai akibat maturasi proses berkemih yang terlambat, umumnya tidak ditemukan kelainan organik yang nyata sebagai penyebab. Inkontinensia urin didefinisikan sebagai pengeluaran urin yang terjadi tanpa kontrol (involunter) meskipun si pasien berusaha sekuat mungkin menahannya, kencing bisa menetes dan tidak lampias, terjadi seketika. Dalam kenyataan sehari-hari, tidak mudah membedakan enuresis dengan inkontinensia urin. Inkontinensia urin lebih sering bersifat kronik dan progresif. Klasifikasi dapat disusun berdasarkan etiologi, kelainan pola berkemih maupun berdasarkan tingkat lesi neurologik. Pendekatan diagnostik yang lebih mutakhir didasarkan pada hasil pemeriksaan miksiosistoureterografi dan urodinamik yang menggolongkan inkontinensia dalam dua bagian yaitu inkontinensia fungsional dan organik. Dalam periode 11 tahun di Bagian Ilmu Kesehatan Anak FKUI-RSCM Jakarta (1989-2000) tercatat 18 kasus inkontinensia urin, 9 di antaranya tergolong dalam buli-buli neurogenik akibat spina-bifida. Masalah utama yang dihadapi ialah ISK berulang dan gagal ginjal kronik. Penanganan yang baik dan tepat harus dimulai dari upaya diagnostik yang akurat. Prioritas utama ialah pemeliharaan fungsi ginjal, pemberantasan infeksi berulang dengan memperhatikan kondisi neurologis yang diderita. Kerjasama antar disiplin seperti urologi, pediatri dan rehabilitasi medik sangat diperlukan, namun di atas segalanya, perhatian, kesabaran dan dedikasi untuk menolong pasien sangat penting agar kualitas hidup pasien dapat ditingkatkan.

Kata kunci: Sfingter neuropati, disfungsi non-neuropati, inkontinensia struktural

D alam proses berkemih secara normal, seluruh komponen sistem saluran kemih bagian bawah yaitu detrusor, leher buli-buli dan sfingter uretra eksterna berfungsi secara terkordinasi dalam proses pengosongan maupun pengisian urin dalam buli-buli. Bila salah satu bagian tersebut mengalami kelainan maka terjadi gangguan berkemih. ${ }^{1}$

Secara fisiologis dalam setiap proses miksi diharapkan empat syarat berkemih yang normal terpenuhi, yaitu (1) kapasitas buli-buli yang adekuat,

Kepala subbagian Nefrologi, Ilmu Kesehatan Anak FKUI - Rumah Sakit Cipto Mangunkusumo, Jakarta.

Alamat korespondensi:

Dr. Taralan Tambunan, Sp.A(K).

Bagian Ilmu Kesehatan Anak FKUI-RSCM, Jl. Salemba 6, Jakarta 10430 Tel. : (021) 391 5179. Fax. : (021) 3913982.
(2) pengosongan buli-buli yang sempurna, (3) proses pengosongan berlangsung di bawah kontrol yang baik, (4) setiap pengisian dan pengosongan buli-buli tidak berakibat buruk terhadap saluran kemih bagian atas dan fungsi ginjal. ${ }^{2}$ Bila salah satu atau beberapa aspek tersebut mengalami kelainan maka dapat timbul gangguan miksi yang disebut inkontinensia urin. ${ }^{2}$

\section{Definisi}

Secara umum gangguan pengeluaran urin yang menyebabkan pakaian atau tempat tidur basah disebut mengompol. Pada usia sekolah mengompol lebih dari satu kali seminggu sudah dianggap abnormal. ${ }^{3}$ Secara sederhana anak yang mengompol dibagi dalam 2 kelompok yaitu enuresis dan inkontinensia urin. ${ }^{3}$ Enuresis berlangsung melalui proses berkemih yang 
normal (normal voiding) tetapi terjadi pada tempat dan waktu yang tidak tepat yaitu berkemih di tempat tidur atau menyebabkan pakaian basah, dapat terjadi pada saat tidur malam hari (enuresis nokturnal), siang hari (enuresis diurnal), ataupun siang dan malam hari. ${ }^{3}$

Enuresis dianggap sebagai akibat maturasi proses berkemih yang terlambat, ${ }^{4}$ umumnya tidak ditemukan kelainan organik yang nyata sebagai penyebab. ${ }^{5}$ Dalam berbagai kepustakaan yang ada ternyata definisi inkontinensia urin tidak seragam sehingga interpretasi dan analisa epidemologik akan bervariasi pula. Dengan demikian angka kejadian serta prevalensi inkontinensia yang sesungguhnya sulit ditentukan. ${ }^{6}$ The International Continence Society (ICS) menyusun definisi inkontinensia urin yaitu suatu keadaan pengeluaran urin yang involunter yang mengakibatkan masalah kesehatan dan sosial dan secara obyektif dapat diperagakan. ${ }^{7}$ Definisi ini kurang ideal untuk tujuan epidemologik. Definisi yang lebih sederhana inkontinensia urin yaitu mengompol yang terjadi tanpa kontrol meskipun si pasien berusaha sekuat mungkin menahannya, kencing menetes dan tidak pernah lampias, terjadi di mana saja dan kapan saja dan sering menyebabkan rasa malu dan frustasi bagi pasien. ${ }^{3}$

Dalam kenyataan tidak mudah membedakan enuresis dengan inkontinensia urin karena tidak ada gejala yang spesifik untuk membedakan keduanya secara jelas. ${ }^{3}$ Dalam makalah ini yang akan dibahas selanjutnya hanya terbatas pada masalah inkontinensia urin.

\section{Etiologi}

Inkontinensia urin dapat bersifat sementara ${ }^{5}$, tetapi lebih sering bersifat kronik dan progresif. Inkontinensia sementara misalnya pada seorang ibu pasca persalinan atau pada sistitis. Inkontinensia kronik dapat disebabkan oleh berbagai etiologi dan digolongkan sebagai berikut : ${ }^{8}$

- Inkontinensia anatomik atau inkontinensia tekanan (stress incontinence)

- Inkontinensia desakan (urge incontinence)

- Inkontinensia neuropati/neurogenik

- Inkontinensia kongenital

- Inkontinensia semu (false = overflow incontinence)

- Inkontinensia post trauma atau inkontinensia iatrogenik

- Inkontinensia fistula

\section{Klasifikasi}

Selain berdasarkan etiologi, inkontinensia atau disfungsi vesiko-ureteral dapat pula digolongkan dengan berbagai cara antara lain berdasarkan kelainan pola berkemih, misalnya buli-buli otonom, berdasarkan tingkat lesi neurologik misalnya tipe upper motor neuron dan lower motor neuron atau hanya berdasarkan lesi perifer yang timbul (buli-buli hipertonik atau atonik) dan sebagainya. Namun klasifikasi seperti tersebut di atas kurang bermanfaat secara klinis maupun penanganannya. ${ }^{2}$ Pendekatan yang lebih mutakhir didasarkan pada hasil pemeriksaan miksio-sisto uretrografi (MSU) dan urodinamik, ${ }^{3,9}$ yang menggolongkan inkontinensia dalam 2 bagian yaitu inkontinensia fungsional dan organik. Namun ada juga kepustakaan yang langsung membagi menjadi 3 kelompok yaitu disfungsi buli-buli - sfingter neuropati, disfungsi non neuropati dan inkontinensia struktural akibat kelainan anatomik. ${ }^{10}$

Berbagai bentuk klinik inkontinensia fungsional atau dikenal pula sebagai non neuropathic bladdersphincter dysfunction antara lain ialah

1. Inkontinensia desakan (urge syndrome and urge incontinence). Inkontinensia timbul akibat kontraksi detrusor yang tidak dapat dihambat pada fase pengisian buli-buli atau pada saat yang bersamaan dilawan oleh kontraksi otot-otot dasar panggul secara volunter (disebut hold manoeuvres) untuk mencegah atau mengurangi terjadinya mengompol, namun biasanya masih terjadi juga pengeluaran sedikit urin. Hold manoeuvres dapat juga dilakukan dengan posisi jongkok (squatting). Sindrom urge sering disertai gejala konstipasi dengan feses yang mengeras dan kadang-kadang sulit dibedakan dengan enkopresis yang timbul pada enuresis diurnal. ${ }^{3}$ Sindrom urge perlu dipikirkan pada kasus refluks-vesiko-ureter (RVU) dengan infeksi saluran kemih (ISK) berulang.,99 Sindrom urge atau inkontinensia desakan dapat dicetuskan oleh peninggian tekanan intra abdomen misalnya pada saat melompat atau bila tertawa. Salah satu contoh ialah Giggle incontinence yang timbul setelah tertawa meskipun buli-buli belum terisi penuh. 3 .,5 Presentasi klinik yang agak aneh ini sulit disembuhkan dan biasanya anak yang 
menderita sindrom ini menghindari ketawa agar tidak mengompol.

2. Staccato voiding ${ }^{3}$ atau dysfunctional voiding. ${ }^{10}$ Kelainan ini disebut juga dyssynergic voiding, ditandai dengan berkemih yang tiba-tiba berhenti secara periodik akibat kontraksi otot-otot dasar panggul secara ritmik. Kelainan ini analog dengan dissinergia detrusor sfingter pada disfungsi bulibuli neurogenik.

3. Fractionated and incomplete voiding. Kelainan ini timbul akibat kurangnya aktivitas otot detrusor. Pancaran urin sangat iregular, pasien sering mengedan untuk memperlancar aliran urin. Biasanya kapasitas buli-buli menjadi besar dan kencing tidak lampias.

4. Lazy bladder syndrome. Sindrom ini merupakan kelanjutan dari fractionated and incomplete voiding. Akibat jangka lama kurangnya aktivitas otot detrusor menyebabkan buli-buli makin membesar dan berdilatasi, bahkan akhirnya otot detrusor tidak mampu berkontraksi lagi. Satu-satunya upaya untuk berkemih hanya mengandalkan tekanan abdomen. Akibatnya residu urin makin meningkat, infeksi makin sering terjadi. Buli-buli seperti malas berkontraksi, miksi makin jarang dan akhirnya timbul inkontinensia karena buli-buli sudah sangat penuh. Penanganan umumnya bersifat konservatif dengan miksi berulang (double atau tripple micturition). ${ }^{10}$

5. Sindrom Hinman. ${ }^{3,10-11}$ Sindrom ini ditandai dengan retensi urin dengan miksi yang tersendatsendat (intermittent voiding pattern), sama seperti kasus buli-buli neurogenik tetapi tanpa kelainan anatomik maupun neurologik. Timbul mulai anak belajar toilet training. Sering disertai ISK berulang, mengompol siang dan malam. Gambaran urodinamik berupa dissinergia detrusor sfingter. Etiologi belum diketahui dan diduga disebabkan kombinasi berbagai faktor dan peranan faktor psikologik cukup dominan di samping faktor sosial ekonomi dan perbedaan budaya. Penanganan terutama berupa psikoterapi di samping penanganan terhadap infeksi dan gangguan fungsi ginjal.

\section{Inkontinensia Organik}

Penyebab organik disfungsi buli-buli pada anak dapat digolongkan dalam 3 jenis kelainan, yaitu kelainan bawaan dan berhubungan dengan gangguan neurologis, kelainan anatomik yang menyebabkan gangguan fungsi saluran kemih bagian bawah serta kelainan yang didapat seperti yang tertera pada Tabel $1 .{ }^{1}$

Di antara ketiga jenis kelainan tersebut mielodisplasia merupakan kelainan yang tersering menyebabkan terjadinya buli-buli neurogenik (neurogenic bladder dysfunction) pada anak, dan di antara kelainan mielodisplastik tersebut meningomielokel merupakan kasus terbanyak (90\%).

\section{Buli-buli Neurogenik}

Inkontinensia yang timbul sekunder akibat neuropati disebut buli-buli neurogenik. Buli-buli

Tabel 1. Penyebab Disfungsi Buli-buli pada Anak

Gangguan sistem saraf pusat

- Spinal

Mielodisplasia

Disrafisme spinal okulta

Agenesia sakrum

Trauma

- Otak dan batang otak

Palsi serebral

Trauma

Ensefalopati

\section{Kelainan anatomik}

- Buli-buli

Ekstrofia

Ektopik ureter bilateral

- Uretra

Valvula uretra posterior $=$ katup uretra posterior

Epispadia

Sinus urogenital

Ektopik ureter bilateral

Kelainan fungsional didapat

Hipertonia dengan kapasitas kecil

Hiperrefleksia

Lazy bladder syndrome

Non neuropati psikogen

Dimodifikasi dari Atala A dan Baner SB, $1999^{1}$ 
neurogenik merupakan kelainan organik yang perlu mendapat perhatian karena kasus inilah yang paling sering ditemukan sebagai akibat meningomielokel. ${ }^{1-}$ ${ }^{2,12}$ Konsekuensi utama akibat buli-buli neurogenik ialah kerusakan ginjal dan inkontinensia urin. ${ }^{12}$ Kerusakan ginjal berkaitan dengan peninggian tekanan intra-vesika atau adanya refluks vesiko ureteral sebagai penyerta dan timbulnya infeksi saluran kemih. Infeksi, refluks dan obstruksi sering ditemukan secara bersama-sama pada buli-buli neurogenik. ${ }^{2,10}$ Mekanisme timbulnya inkontinensia sangat beragam dan sering merupakan kelainan ganda. Sedikitnya ada empat pola gambaran urodinamik yang dapat ditemukan pada buli-buli neurogenik, yaitu ${ }^{13}$

- Hiperefleksia otot detrusor bersama-sama dengan hiperrefleksia (spastisitas) sfingter

- Arefleksia otot detrusor bersama-sama dengan arefleksia sfingter

- Arefleksia otot detrusor bersama-sama dengan hiperrefleksia (spastisitas) sfingter

- Hiperrefleksia otot detrusor bersama-sama dengan arefleksia sfingter

Manifestasi klinik inkontinensia yang timbul akan bervariasi tergantung pada intensitas dan kombinasi kelainan urodinamik yang ditemukan. ${ }^{13}$ Ringkasnya buli-buli bisa normal atau kapasitasnya kecil, otot detrusor bisa akontraktil atau kontraktil (biasanya hiperrefleks), leher buli-buli bisa kompeten atau inkompeten. Sedangkan mekanisme sfingter distal dapat normal, inkompeten atau malah obstruktif (bisa dalam bentuk disinergia detrusor sfingter atau obstruksi statik sfingter distal). ${ }^{2}$

\section{Prevalensi dan Insidens}

Berbagai kepustakaan melaporkan insidens maupun prevalensi berdasarkan keluhan seperti mengedan, polakisuria, ngompol sehingga diagnosis definitif yang ditegakkan berbeda satu sama lain. ${ }^{3}$ Dengan adanya kesimpang-siuran mengenai diagnosis inkontinensia urin timbullah masalah dalam menilai sensitivitas dan spesifisitas penemuan gejala/tanda klinik secara epidemiologik. Variasi dalam interpretasi diagnostik akan mempengaruhi prevalensi inkontinensia pada berbagai penelitian, sehingga prevalensi yang lebih akurat sulit ditentukan. ${ }^{3,6}$ Meskipun demikian diperkirakan sekitar 20\% kasus poliklinik nefrologi anak terdiri dari kasus-kasus kompleks ISK berulang - inkontinensia fungsional atau disfungsi sfingter non neuropati. ${ }^{3}$

Di antara kelompok buli-buli neurogenik, mielodisplasia merupakan etiologi tersering dan $90 \%$ di antaranya berupa mielomeningokel. ${ }^{10}$ Data yang dapat dikumpulkan dari kasus rawat jalan maupun rawat inap di Bagian Ilmu Kesehatan Anak RSCM selama 11 tahun diperoleh 18 kasus inkontinensia urin, sebagian di antaranya diagnosis definitif belum dapat ditegakkan, ${ }^{14}$ namun di antara kasus yang terdiagnosis lebih spesifik, buli-buli neurogenik akibat spina bifida cukup dominan (9 kasus) seperti yang tertera pada Tabel 2. Semua kasus disertai dengan ISK berulang dan pada pengamatan ternyata 11 kasus di antaranya sudah mengalami gagal ginjal kronik.

\section{Diagnosis}

Penanganan yang baik dan tepat harus dimulai dari

Tabel 2. Inkontinensia pada Anak di RS Dr. Cipto Mangunkusumo, Jakarta (Jan 1989 - Apr 2000) ${ }^{13}$

\begin{tabular}{lccc}
\hline Jenis kelainan & Laki-laki & Perempuan & Jumlah \\
\hline $\begin{array}{l}\text { Disfungsi buli-buli - sfingter neuropati } \\
\text { (buli-buli neurogenik) }\end{array}$ & 3 & 6 & 9 \\
$\begin{array}{l}\text { Disfungsi buli-buli-sfingter non neuropati } \\
\text { Kelainan struktural / anatomik }\end{array}$ & 4 & 2 & 6 \\
\hline Jumlah & 1 & 2 & 3 \\
\hline
\end{tabular}


upaya diagnostik yang akurat, oleh sebab itu pendekatan serta tahapan diagnostik harus diikuti dengan seksama agar hasil penanganan mencapai sasaran yang optimal. Tahapan diagnostik meliputi anamnesis yang teliti dan pemeriksaan fisis yang seksama. ${ }^{2-3,14}$ Dengan anamnesis dan pemeriksaan fisis yang seksama diharapkan sudah dapat dibedakan antara enuresis primer (enuresis nokturna) dengan inkontinensia urin. ${ }^{3} \mathrm{Hal}$-hal yang perlu ditanyakan antara lain pola berkemih (voiding) dan mengompol, frekuensi dan volume urin, kebiasaan defekasi serta pola kepribadian. Pemeriksaan fisis meliputi perkembangan psikomotor, inspeksi daerah genital dan punggung, refleks lumbosakral dan pengamatan terhadap pola berkemih. ${ }^{9}$

Tahapan diagnostik yang diajukan oleh van Gool seperti tertera pada Gambar 1 dapat dipakai sebagai acuan dan sekaligus pemilihan uji diagnostik yang diperlukan. ${ }^{3}$

Tahapan diagnostik berikutnya ialah pemeriksaan penunjang baik laboratorik maupun pencitraan. Urinalisis, biakan urin, pemeriksaan kimia darah dan uji faal ginjal perlu dilakukan terhadap semua kasus inkontinensia urin. ${ }^{1,10,12,15}$ Ultrasonografi dipakai sebagai pilihan pertama pencitraan sebagai penyaring, kemudian dapat dilanjutkan dengan miksio-sistouretrografi (MSU). Nilai pemeriksaan USG dapat ditingkatkan bila sekaligus diperiksa pre dan post miksi serta kecepatan aliran urin untuk mendeteksi kemungkinan obstruksi sfingter buli-buli. ${ }^{10,15}$

Pemeriksaan urodinamik terindikasi pada kasus yang diduga buli-buli neurogenik yang tidak selalu dapat terdiagnosis hanya berdasarkan pemeriksaan fisis-neurologis. ${ }^{12,15}$ Pemeriksaan urodinamik hanya diperlukan pada kasus-kasus yang belum jelas diagnosisnya dengan pemeriksaan baku seperti USG dan MSU. ${ }^{10}$ Patut diingat bahwa pemeriksaan urodinamik pada anak memerlukan waktu yang banyak dan membutuhkan kesabaran karena demikian banyaknya instruksi yang harus diberikan dan tahapan pemeriksaannya sangat menyita waktu yang banyak. ${ }^{1}$

Tidak semua rumah sakit memiliki alat urodinamik, namun di rumah sakit yang memiliki klinik inkontinensia atau klinik spina bifida, seyogyanyalah alat ini tersedia. ${ }^{2}$ Namun meskipun alat tersedia, tidak semua dokter spesialis anak mau memanfaatkannya karena alasan rumitnya pemeriksaan dan menyita waktu. Meskipun tanpa pemeriksaan urodinamik, sebenarnya sebagian besar kasus inkontinensia sudah dapat ditangani dengan baik hanya dengan pemeriksaan konvensional yang ada asal dimanfaatkan secara optimal. $^{2}$

\section{Tatalaksana}

Penanganan kasus-kasus inkontinensia urin harus memperhatikan berbagai aspek antara lain sebagai berikut $^{2}$

- Prioritas utama ialah pemeliharaan fungsi ginjal

- Penanganan disfungsi vesiko-uretral ditujukan terhadap kelainan yang ditemukan secara nyata

- Penanganan harus realistis dengan memperhatikan kondisi neurologis yang diderita

- Penanganan adekuat terhadap infeksi yang menyertai disfungsi vesiko-ureteral

Dengan kata lain penanganan adekuat meliputi pengosongan buli-buli dengan baik, penurunan tekanan intravesika, pencegahan ISK serta penatalaksanaan terhadap inkontinensia sendiri tercapai, terutama pada anak yang cukup besar. ${ }^{12}$

Rencana penanganan harus melihat kondisi kasus demi kasus. Tahapan permulaan meliputi identifikasi gangguan fungsi ginjal serta pengobatannya. Bila sudah sempat terjadi gangguan fungsi ginjal umumnya berkaitan dengan obstruksi aliran urin, baik sebagai akibat dissinergia detrusor-sfingter atau stasis akibat obstruksi sfingter uretra distal. Bila disertai refluks vesikoureter maka gangguan fungsi ginjal semakin berat. $^{2,12}$

Tahap berikutnya ialah evaluasi terhadap inkontinensia apakah perlu segera ditangani atau tidak. Pada anak berusia 2-3 tahun misalnya penanganan terhadap inkontinensia dapat ditunda sampai usia di mana inkontinesia yang dialami menimbulkan masalah sosial atau membuat malu pasiennya. Selanjutnya ialah penilaian apakah kondisi pasien memungkinkan untuk suatu tindakan, misalnya seorang anak dengan kelainan neurologis dan urologis yang berat, pemakaian kateter dauer tampaknya lebih rasional dibandingkan dengan usaha lain yang lebih sulit dan lebih invasif.

Tahapan selanjutnya ialah penilaian apakah ada tindakan khusus yang dapat dilakukan. Dalam hal ini pemeriksaan urodinamik diharapkan dapat memberi gambaran yang lebih akurat untuk menentukan tindakan apa yang sebaiknya dilakukan. 


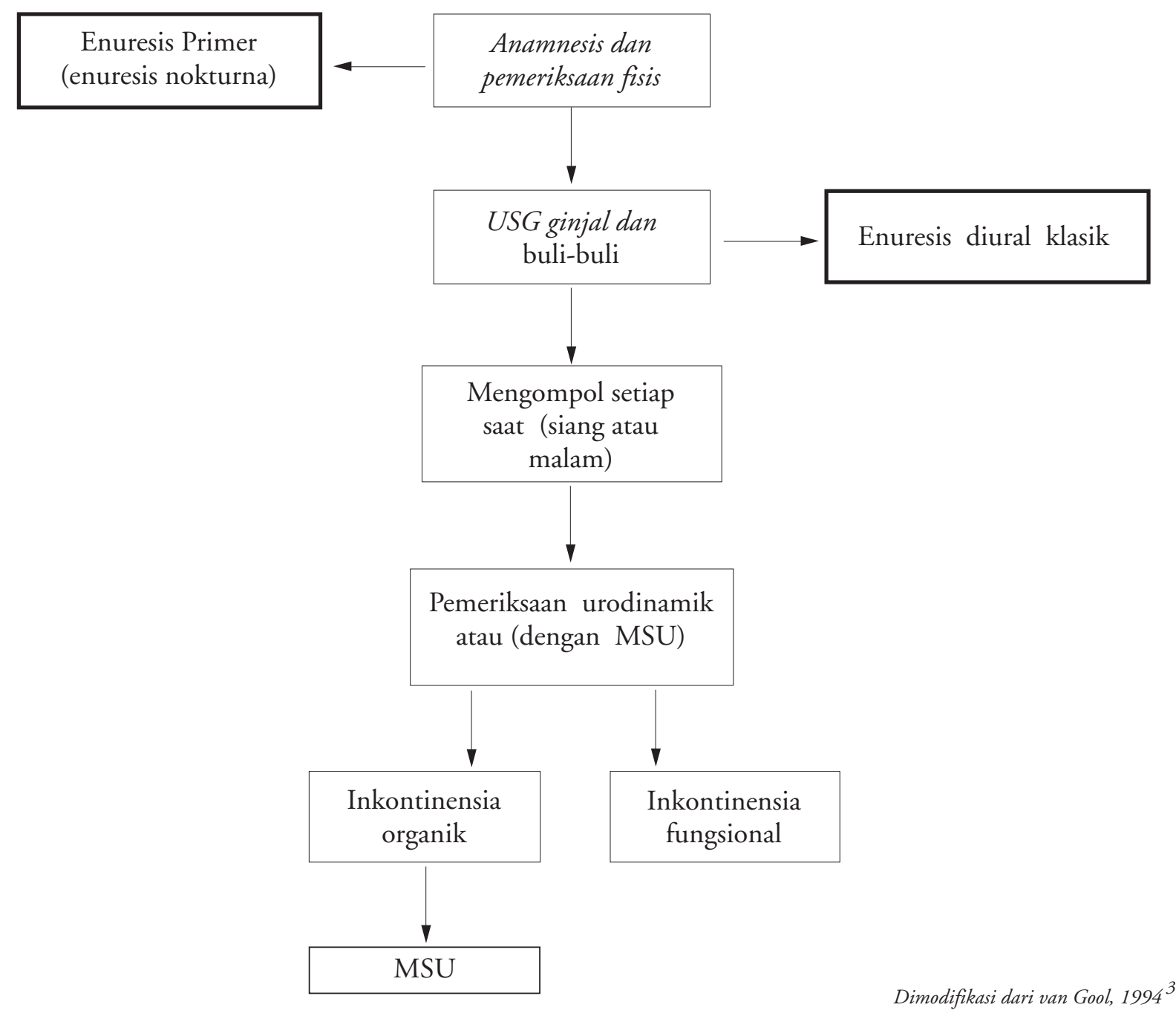

\section{Gambar 1. Tahapan diagnostik mengompol pada anak}

Untuk ini peranan subspesialistis sangat diperlukan, demikian juga kerja sama antar disiplin seperti urologi, neurologi, pediatri dan rehabilitasi medik sangat dibutuhkan. Alternatif tindakan dapat berupa pengobatan medikamentosa seperti pemberian oksibutinin, imipramin dan sebagainya atau berupa tindakan urologik seperti sistoplastik, pemasangan sfingter artifisial atau hanya sekedar clean intermittent catheterisation (CIC). ${ }^{2}$ Pengeluaran urin secara $\mathrm{Cred}^{1}$ tidak dianjurkan karena tindakan ini dapat memperburuk refluks yang sudah ada dan dapat pula memperburuk fungsi ginjal. ${ }^{1}$

Tindakan lain seperti rekonstruksi leher buli-buli, stimulasi elektrik serta obat-obatan sejenis betanechol, distigmin untuk mengurangi dissinergia detrusorsfingter pada umumnya kurang bermanfaat. ${ }^{2} \mathrm{Di}$ atas segalanya, perhatian, kesabaran dan dedikasi untuk menolong pasien sangat penting untuk meningkatkan kualitas hidup kasus yang ditangani. ${ }^{12}$

\section{Daftar Pustaka}

1. Atala A, Baner SB. Bladder dysfunction. Dalam: Barrat TM, Avner ED, Harmon WE, penyunting. Pediatric Nephrology. $4^{\text {th }}$ ed. Baltimore: Lippincot William \& Wilkins, 1999. h. 913-30.

2. Mundy AR. The neuropathic bladder. Dalam: Postlehwaite RJ penyunting. Clinical Paediatric 
Nephrology. $2^{\text {nd }}$ ed. Oxford: Butterworth-Heinemann, 1994. h. 319-33.

3. Van Gool JD. Disorders of micturition. Dalam: Postlehwaite RJ, penyunting. Clinical Paediatric Nephrology. $2^{\text {nd }}$ ed. Oxford: Butterworth-Heinemann, 1994. h. 59-74.

4. Jarvelin MR, Moilanen I, Kangas P, Morning K, Vikevainen-Tervonen L, Huttunen NP, Seppanen J. Aetiological and precipitating factors for childhood enuresis. Acta Paediatr Scand 1991; 80:361-9.

5. Meadow SR. Day wetting. Pediatr Nephrol 1990; 4:178-84.

6. Hunshar S, Arnold EP, Burgio K, Diokuo AC, Herzog AR, Mallet VT. Epidemology and natural history of urinary incontinence. Dalam: Abrams P, Khoury S, Wein $A$, penyunting. Incontinence. $1^{\text {st }}$ International consultation on incontinence. 1998, Monaco June 28 July 1, 1998; 199-226.

7. Abrams P, Blaivas JG, Stanton SL, Andersen JT. The standarisation of terminology of lower urinary tract function. Scand J Urol Nephrol 1988; Supp; 114:5 dikutip dari Hunshar S, Arnold EP, Burgio K, Diokuo AC, Herzog AR, Mallet VT. Epidemology and natural history of urinary incontinence. Dalam: Abrams P, Khoury S, Wein A, penyunting. Incontinence. $1^{\text {st }}$ International consultation on incontinence. 1998, Monaco June 28 - July 1, 1998:199-226.

8. Tanagho EA. Urinary incontinence. Dalam: Tanagho EA, MC Aninch JW, penyunting. Smith General Urology. $14^{\text {th }}$ ed. California, Appleton and Lange, 1995. h. 536-
51.

9. Van Gool JD, Bloom DA, Butter RJ, Djurhuus JC, Hjalmas K, de Jong TPVM, Kaplan WE, Peters CA, Podesta ML. Conservative management in children. Dalam: Abrams P, Khoury S, Wein A, penyunting. Incontinence. First international consultation on incontinence. Monaco, June 28-July 1, 1998; 487-549.

10. Varlan DE, Dippel J. Non neurogenic bladder and chronic renal insufficiency in childhood. Pediatr Nephrol 1995; 9:1-5.

11. Fernandes ET, Reinberg Y, Vernier R, Gonzales R. Neurogenic bladder dysfunction in children: Review of pathophysiology and current management. J Pediatr 1994; 124:1-7.

12. Madersbacher H, Windaele JJ, Igawa Y, Chartier-Kastler E, Fall M, Kovindka A, Perkash I, Pesce F. Conservative management in the neuropathic patient. Dalam: Abrams P, Khoury S, Wein A, penyunting. Incontinence. First international consultation on incontinence. Monaco, June 28 - July 1, 1998; 775-95.

13. Tambunan T, Trihono PT, Pardede SO. Urinary incontinence in children in Cipto Mangunkusumo Hospital Jakarta. A serial case report. Paediatr Indones (dalam proses pencetakan).

14. Duckett JW, Raezer DM. Neuronuscular dysfunction of the lower urinary tract. Dalam: Kelalis PP, King LR, Belman AB, penyunting. Clinical Paediatric Urology. Philadelphia, WB Saunders Co, 1976. h. 401-26.

15. Malone PSJ. The management of urinary incontinence. Arch Dis Child 1997; 77:175-8. 